\title{
Correction
}

\section{Correction: Pfeiffenberger et al., Ephrin-As and Patterned Retinal Activity Act Together in the Development of Topographic Maps in the Primary Visual System}

In the article "Ephrin-As and Patterned Retinal Activity Act Together in the Development of Topographic Maps in the Primary Visual System" by Cory Pfeiffenberger, Jena Yamada, and David A. Feldheim, which appeared on pages 12873-12884 of the December 13, 2006 issue, the authors regret an error in Figure 8 where the EphA/ephrin-A gradients of expression were flipped in the SC. The interpretation and conclusions of the study are not affected. The correct Figure 8 is shown below.

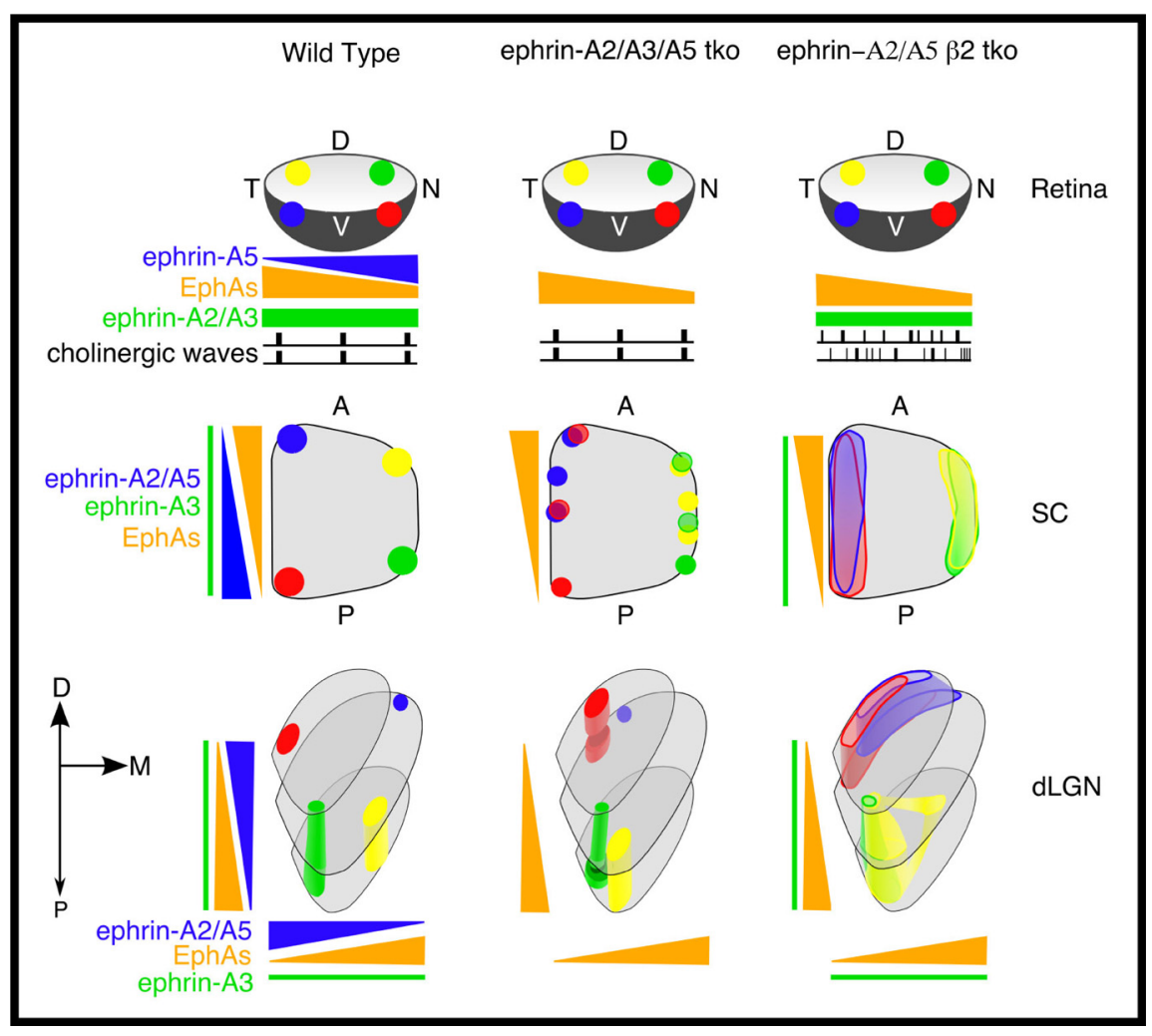

Figure 8.

DOI: 10.1523/JNEUROSCI.0064-13.2013 